\title{
Estimation of fatigue life for clinched joints with the Local Strain Approach incorporating the impact of cold forming to cyclic material properties
}

\author{
Boris Spak $^{1}$, Maximilian Schlicht ${ }^{2}$, Karina Nowak $^{2}$, Markus Kästner ${ }^{1}$, Pascal Froitzheim², \\ Wilko Flügge ${ }^{2}$, and Melanie Fiedler ${ }^{1^{*}}$ \\ ${ }^{1}$ Chair of Computational and Experimental Solid Mechanics, Technische Universität Dresden, 01062 \\ Dresden, Germany \\ ${ }^{2}$ Fraunhofer Institute for Large Structures in Production Engineering IGP, 18059 Rostock, Germany
}

\begin{abstract}
Joining by forming is a commonly applied technique in the automotive industry to assemble parts of thin metal sheets to meet the demands of lightweight design. The joining operation induces changes in material behaviour due to cold forming, that can be observed in increased hardness in the area close to the joint neck compared to the base material. Complex geometrical features of clinched joints on a small scale and the lack of non-destructive methods to track local stresses and strains require a combined approach utilizing numerical and experimental techniques. Numerical process and loading simulation are performed utilizing commercial finite element software LS-Dyna ${ }^{\circledR}$. Hardness measurements in the joint are carried out to assess the impact of forming operation. Cyclic material properties are derived from Vickers hardness to estimate fatigue life with the Local Strain Approach using the damage parameter PSWT. Fatigue life estimation with failure criterion crack initiation obtained from simulation results is compared to those from experiments. The results obtained indicate that the Local Strain Approach is suitable for fatigue life estimations of clinched joints under constant amplitude loading as long as the influence of the forming process is considered.
\end{abstract}

\section{Introduction}

Mechanical clinching is an efficient joining technique used in automotive industry and manufacturing of white goods. Two or more sheets are joined through localized cold forming without additional fasteners. Different variants exist, such as clinching with fixed grooved dies, extensible dies, shear clinching and flat clinching, resulting in joints with distinctive joint properties [1]. Extensive research, both through experimental work and numerical simulation, has been conducted so far to better understand the material flow in the contact region during forming operation [2-4]. To leverage an even broader application in manufacturing lightweight products, efforts has been undertaken to further develop joining tools and introduce modifications to existing processes to successfully join metallic sheets with low ductility [5] and combination of sheets from different materials [6]. Current research 
activities focus on consideration of the joining operation in process chains using meta models [7] while stressing the importance of the consideration of change in material properties due to forming history. A significant increase in hardness in the neck region of the joint and joint bottom is observed compared to base material [8]. In these areas the degree of forming reaches a maximum. The cold forming of the material is assumed to introduce significant changes in cyclic material properties, thus resulting in experimentally obtained higher fatigue life compared to estimation based on numerical estimation [9].

The present study focuses on the fatigue life estimation with the Local Strain Approach (LSA) taking into account the forming history including changes of cyclic material properties due to cold working. Previous attempts in estimating fatigue life for clinched joints with LSA rendered very conservative results [10]. Failure criterion is crack initiation. Following a material characterization of the aluminum wrought alloy under quasi-static loading, the clinch joint geometry with a fixed grooved die is established using a numerical 2D finite element simulation with symmetry assumption about the rotational axis. The result of the process simulation is mapped to a $3 \mathrm{D}$ model. In strain controlled fatigue test with constant strain amplitudes and strain ratio of $R_{\varepsilon}=-1$, the cyclic material properties of the base material are obtained. The loading simulation is performed using elastic-plastic material behavior directly in two ways: 1) using the base material in clinched joint and surrounding sheet material, 2) assigning different cyclic material properties to regions identified through hardness measurements in the clinched joint. Fatigue life estimation for both approaches is compared to experimental results from lap shear specimen loaded with stress ratio $R=0.1$.

\section{Fatigue life estimation}

Being a material-based concept, the LSA can be applied to estimate fatigue life for different geometries as long as the material cyclic properties are known from experiment or estimation. LSA is based on the experimentally proven assumption [11] that a notched specimen will experience the same amount of number of cycles to crack initiation as a smooth laboratory specimen if exposed to identical cyclic strain history in the notch root. With the identified critical location, either from a Finite Element Analysis or from experimental observations, approaches exist to estimate fatigue life from a numerical simulation with linear-elastic material behaviour in conjunction with a revaluation, such as the Neuber's rule [12]. To capture the elastic-plastic material behaviour, Ramberg-Osgood [13] equation

$$
\varepsilon=\frac{\sigma}{E}+\left(\frac{\sigma}{K^{\prime}}\right)^{\frac{1}{n^{\prime}}}
$$

can be utilized. Alternatively, the numerical simulation can be carried out directly using elastic-plastic material behaviour. To compute the stress-strain- path from a known loading sequence in a numerical simulation, special care needs to be taken to capture properly the memory effects and Masings's law [14]

$$
\Delta \varepsilon=\frac{\Delta \sigma}{E}+2\left(\frac{\Delta \sigma}{2 K^{\prime}}\right)^{\frac{1}{n^{\prime}}}
$$

that generally describes kinematic hardening. In case of $R=0.1$, isotropic and kinematic hardening produce identical results. From the stress-strain-path, the closed hysteresis are determined. It is assumed that each closed hysteresis contributes a certain amount of damage. In the present study the Smith-Watson-Topper damage parameter [15]

$$
P_{S W T}=\sqrt{\left(\sigma_{a}+\sigma_{m}\right) \cdot \varepsilon_{a} \cdot E}
$$


is used to calculate the damage of closed hysteresis loops and of the residuum. The parameters of the strain Wöhler-Curve

$$
\varepsilon_{a}=\frac{\sigma_{f}}{E} \cdot\left(2 N_{f}\right)^{2 b}+\varepsilon_{f}^{\prime} \cdot\left(2 N_{f}\right)^{2 c}
$$

are obtained from strain controlled fatigue tests with constant strain amplitudes and a strain ratio of $R_{\varepsilon}=-1$ or estimated from either hardness or ultimate tensile strength, see [16]. The damage parameter Wöhler-Curve

$$
P_{S W T}=\sqrt{\sigma_{f}^{\prime 2} \cdot\left(2 N_{f}\right)^{2 b}+\sigma_{f}^{\prime} \cdot \varepsilon_{f}^{\prime} \cdot E \cdot\left(2 N_{f}\right)^{b+c}}
$$

serves to compare the damage from hysteresis counting with the number of cycles to failure, i. e. crack initiation. The Miner rule

$$
D=\sum_{i=1}^{m} \frac{1}{N_{f, i}}
$$

is commonly applied, with the assumption that failure will initiate if $D=1$.

\section{Numerical simulation}

\subsection{Process simulation of mechanical clinching}

In the study at hand the heat treatable aluminum wrought alloy EN AW-6060 T66 is considered. The material was supplied in $2 \mathrm{~mm}$ thick sheets. The chemical composition, obtained via optical emission spectrometry, is presented in Table 1.

Table 1. Chemical composition of investigated aluminum alloy [wt\%].

\begin{tabular}{lllllllll}
\hline Material & $\mathrm{Si}$ & $\mathrm{Fe}$ & $\mathrm{Cu}$ & $\mathrm{Mn}$ & $\mathrm{Mg}$ & $\mathrm{Cr}$ & $\mathrm{Zn}$ & $\mathrm{Ti}$ \\
\hline EN AW-6060 T66 & 0.45 & 0.18 & 0.02 & 0.04 & 0.44 & 0.01 & 0.01 & 0.02 \\
\hline
\end{tabular}

The flow curve to be used in the process simulation, is determined from quasi-static tension tests in compliance with DIN EN ISO 6892-1 on dog bone specimen manufactured according to German standard DIN 50125. After applying a speckle pattern on the flat surface of the specimen, full field measurement of displacements is conducted with digital image correlation system GOM Aramis to obtain the mechanical properties: yield strength $R_{p 02}=233 \mathrm{MPa}$, ultimate tensile strength $R_{m}=247 \mathrm{MPa}$, Young's modulus $E=65.165 \mathrm{MPa}$ and Poison ratio $v=0.332$. Strains are computed from the displacement measurements up to onset of necking. In mechanical clinching, a high degree of deformation can be expected with $\varphi \approx 2 \ldots 3$. In quasi-static loading, the material fails on average at $10 \%$ engineering strain. Thus, for greater degrees forming an extrapolation according to Voce [17] is applied for the yield stress $\sigma_{f}$.

$$
\sigma_{f}(\varphi)=295.93 M P a-(295.93 M P a-233 M P a) \cdot e^{-16.48 \varphi}
$$

To reduce computation time, the process simulation is carried out as 2D model exploiting the symmetry about the rotational axis of the clinched joint with a fixed grooved die with dimensions equivalent to TOX tooling 10.200 and 14.150, see Fig. 1 a). Commercial finite element software LS-Dyna ${ }^{\circledR}$ R11.1.0 is used with implicit solver. The forming tools are modelled as rigid bodies following the conclusions drawn in [3]. The elastic-plastic material 
behavior is input as a piecewise linear curve, assuming isotropic hardening with a von Mises yield surface. Severe distortions of the sheets are captured implementing $r$-adaptive mesh refinement with minimum edge length of $0.125 \mathrm{~mm}$. Stiffness of the real testing rig TOX ElectricDrive (EPMR) is modelled with elastic discrete elements. Static coefficient of friction is assumed at a value of 0.5 , while the dynamic coefficient is set to 0.25 . The coefficient of viscous friction is set to $133 \mathrm{MPa}$ to limit the friction forces. A displacement boundary condition is applied to establish joints with bottom thickness of $1.0 \mathrm{~mm}$ and $1.4 \mathrm{~mm}$. Validity of the process simulation is assessed by comparing the force-displacement curve of experiment and simulation as well as through comparison of actual micrographs of clinched joints with the ones obtained via numerical simulation, depicted in Fig. 1 b) and c). With the selected set of parameters, the simulation gives overall a satisfactory result in the forcedisplacement curve and cross section if compared to the experiment.
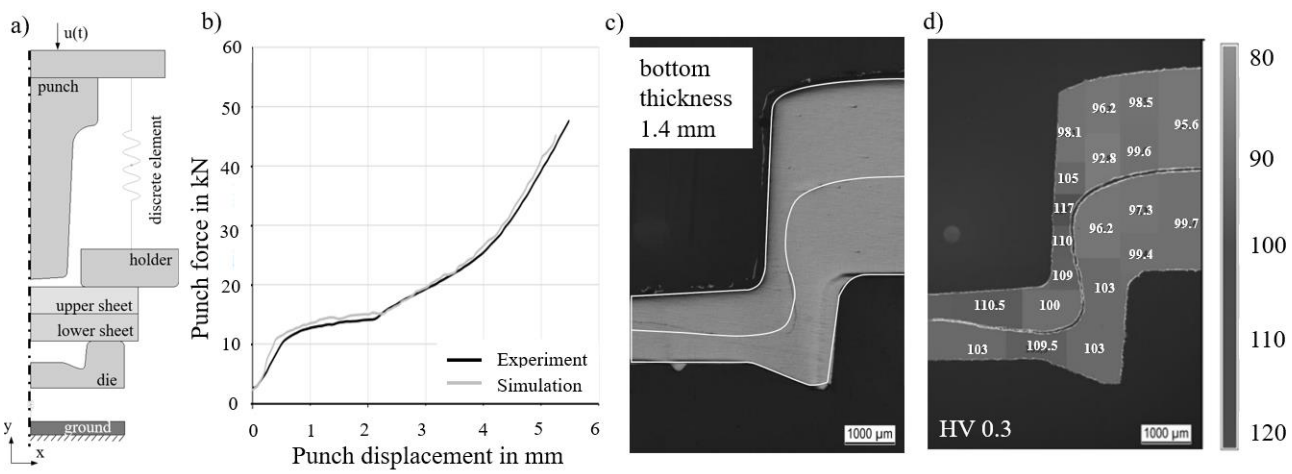

Fig. 1. a) Process simulation of 2D model. b) Force-displacement curve comparison of experiment and simulation. c) Cross section of clinched joint with bottom thickness $1.4 \mathrm{~mm}$ and simulation result (white line). d) Vickers hardness distribution in clinched joint with bottom thickness $1.4 \mathrm{~mm}$ [10].

As a result of joining by cold forming, substantial changes in material properties can be expected. In the study at hand the Vickers hardness is measured by indentation method in compliance with DIN EN ISO 6507-1 in the cross section of the joint. Results are presented in Fig. $1 \mathrm{~d}$ ) on the example of the clinched joint variant with bottom thickness of $1.4 \mathrm{~mm}$. Evidently, a significant change in hardness compared to base material can be observed, especially in the joint neck with HV 117 and bottom of the joint at HV 110, capping out at around $36 \%$ higher than the average hardness of HV 86 in base material.

\subsection{Loading simulation of clinched joints in lap shear specimen}

With the geometry of the clinched joint variants obtained as a result of the process simulation, the loading simulation with implicit solver is set up to mimic the real testing condition of lap shear specimen. The resulting geometry of $2 \mathrm{D}$ process simulation is mapped to a $3 \mathrm{D}$ half model with hexahedral elements using inbuilt features of LS Dyna ${ }^{\circledR}$, applying proper symmetry boundary conditions. The clinched joint is tied to surrounding sheet material with appropriate tied contacts. The contact in between upper and lower sheet is modelled using a penalty formulation with automatic surface detection option while keeping the coefficients of friction the same as in the process simulation. Displacement boundary conditions are applied to the lower sheet to keep it in place. A cyclic load with $R=0.1$ is applied at the face of the upper sheet together with a displacement boundary condition in vertical direction, see Fig. 2d). It is worth mentioning that the process simulation predicts residual stresses (failure location: $\sigma_{\text {res }} \approx-160 \mathrm{MPa}$ ) in the clinched joint, of which the distribution is presented in Fig. 2 a) in terms of von Mises stress. Different approaches exist to consider residual stresses 
in a fatigue life estimation with LSA and has been applied to cold form components as presented in [18]. From the small amount of research results available [19], it is debatable how the residual stress state in conjunction with further cyclic hardening or softening in cyclic loading affect the stress-strain-path in the critical region of clinched joints. Running comparative loading simulations of the clinched joint without and with residual stresses using eq. (1) as input for the elastic-plastic material behavior at a nominal stress amplitude of $6.75 \mathrm{MPa}$, a deviation of $0.53 \%$ in maximum of the first principal stress is obtained after three to four cycles, indicating a relaxation of residual stresses. This extremely rapid relaxation of residual stresses must be questioned and will be discussed further in section 4 .

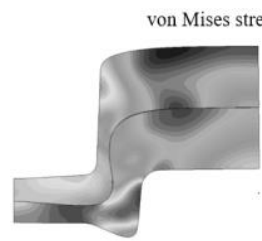

a)

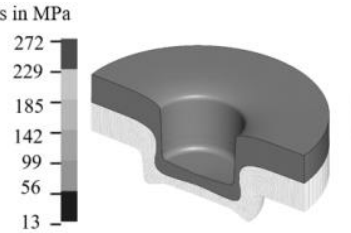

b)

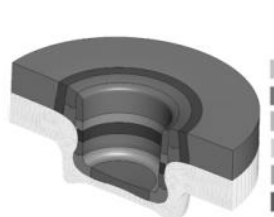

c)

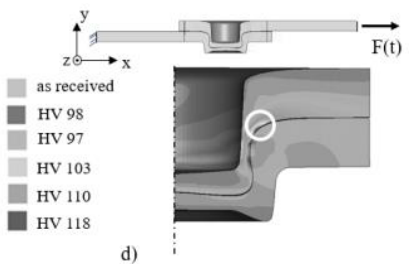

Fig. 2. a) Residual stress distribution in clinched joint as result of process simulation [10]. b) 3D model of clinched joint with base material mechanical properties [10]. c) Clinched joint separated in regions with different cyclic material properties estimated from measured Vickers hardness. d) Location of maximum principle stress used to estimate fatigue life up to crack initiation if failure occurs in transitional area from neck to surrounding sheet material [10].

To account for change in material properties due to forming operation, i. e. hardness increase around the joint neck and joint bottom, the upper sheet is separated in regions as shown in Fig. 2 c), which are assigned different cyclic material properties. Based on the correlation established by the Society of Materials Science Japan [20], the ultimate tensile strength $R_{m}$ of aluminum alloys is estimated using Vickers hardness $H V$

$$
R_{m}=\frac{H V-21.9}{0.242}
$$

With an existing great variety of proposed methods to estimate cyclic material properties, please refer to [21] for a comprehensive summary, the "Uniform Material Law" (UML) is chosen for the study at hand. Table 2 presents the cyclic material properties of the base material in the as received state obtained experimentally as well as parameters of the estimation based on the ultimate tensile strength obtained by Vickers hardness. Fig. 2 d) shows the critical location with the respect to the maximum of first principal stress, that correlates well to the crack location found in physical clinched joints [9].

Table 2. Cyclic material properties for fatigue life estimation with LSA.

\begin{tabular}{llllll}
\hline Material parameter & as received & HV 97 & HV 103 & HV 110 & HV 118 \\
\hline$\sigma_{f}^{\prime}$ in MPa & 455.2 & 518.25 & 559.65 & 607.96 & 663.17 \\
$\mathrm{~b}$ & -0.097641 & -0.095 & -0.095 & -0.095 & -0.095 \\
$\varepsilon_{f}^{\prime}$ & 0.24124 & 0.35 & 0.35 & 0.35 & 0.35 \\
$\mathrm{c}$ & -0.69605 & -0.69 & -0.69 & -0.69 & -0.69 \\
$\mathrm{~K}$ ' in MPa & 428.5 & 499.63 & 539.55 & 586.12 & 639.34 \\
$\mathrm{n}$ & 0.0895 & 0.11 & 0.11 & 0.11 & 0.11 \\
\hline
\end{tabular}




\section{Experimental results}

The fatigue tests have been conducted on lap shear specimen manufactured according to DVS/EFB 3480-1 on a Sincotec Powerswing resonance testing rig with the nominal stress amplitude ranging from $9 \mathrm{MPa}$ to $14.5 \mathrm{~N}$ and stress ratio set to $R=0.1$. Fig. 3 , on the left hand side, presents the experimental results for clinched joints with bottom thickness of 1.0 $\mathrm{mm}$ and $1.4 \mathrm{~mm}$. Both variants show a very similar number of cycles with regards to failure criterion fracture. To obtain the number of cycles to crack initiation, further cyclic experiments were performed with clinched joint specimen with bottom thickness of $1.0 \mathrm{~mm}$. With the assumption, that a change in testing frequency could indicate a crack initiation, a drop in frequency $\Delta \mathrm{f}=0.05 \ldots 0.1 \mathrm{~Hz}$ was defined. If a drop in frequency was detected by testing software, the test run was stopped and a micrograph of the specimen was prepared and examined for cracks in the cross section of the joint. With the described procedure, cracks with a length in the range of $300 \mu \mathrm{m}$ to $600 \mu \mathrm{m}$ could be found in the critical region in the transitional area from joint neck to surrounding sheet material. With $\Delta \mathrm{f}=0.1 \mathrm{~Hz}$, the number of cycles up to crack initiation is close to those corresponding to the failure criterion fracture. A drop in frequency $\Delta \mathrm{f}=0.05 \mathrm{~Hz}$ indicates the initiation of cracks in the clinched joint at a much lower number of cycles. Though, if compared to the sheet thickness of $2 \mathrm{~mm}$, the crack length is relatively large.
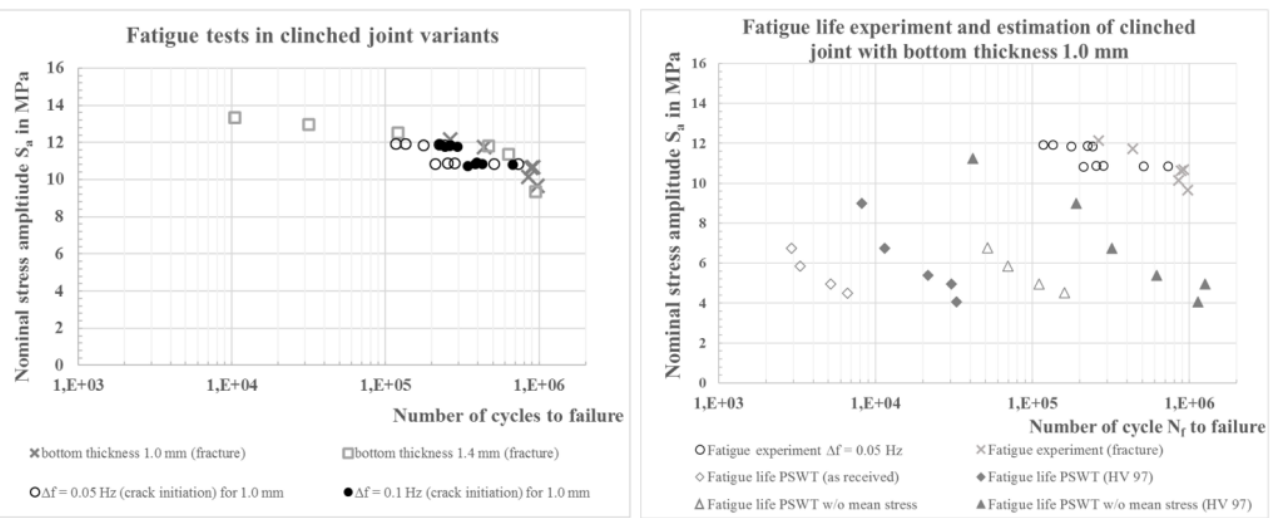

Fig. 3. Left: Fatigue tests up to fracture for clinched joint variants with bottom thickness of $1.0 \mathrm{~mm}$ and $1.4 \mathrm{~mm}$. Crack initiation life for joint with bottom thickness of $1.0 \mathrm{~mm}$. Right: Fatigue life estimation with LSA and damage parameter $P_{S W T}$ for joint with bottom thickness of $1.0 \mathrm{~mm}$.

Fig. 3, on the right hand side, presents the fatigue life estimation with LSA for the clinched joint with bottom thickness of $1.0 \mathrm{~mm}$. Using the equations (3) - (7) with an elasticplastic FE-calculation, the fatigue life estimation with damage parameter $P_{S W T}$ was carried out with the cyclic material properties of the base material in the as received state. The estimation (blank diamonds) gives a significantly lower number of cycles to failure in comparison to the experiments (circles and crosses). A possible explanation might be found in the change of material properties due to cold forming during joining operation. Thus, the fatigue life is estimated using the cyclic material properties of the hardened material and estimation based on Vickers hardness at HV 97, as presented in section 3.2. Consequently, an estimation with increased number of cycles is obtained while still being much lower than experimental results (full diamonds). This leads to the assumptions that either the cold formed material can endure much higher local stresses or is less sensitive to mean stress or the very fast relaxation of residual stresses obtained in the process simulation is wrong and the residual stresses can't be neglected. Due to small geometrical features of the clinched joint, it is 
impossible to retrieve a proper specimen from the neck and bottom region to further investigate the cyclic material properties of the hardened material or measure the residual stresses. In [22] a change of the mean stress sensitivity was observed on specimens of different aluminium alloys in peak aged condition manufactured by equal-channel angular pressing (ECAP). However, it is unclear to what extent the results presented there can be applied to the case at hand, since important information, e.g. on the sample shapes tested, are missing. Thus, an attempt is made by neglecting the mean stress in the fatigue life estimation for the clinched joint explainable by a combination of residual stresses and a reduced mean stress sensitivity. Although the complete neglect of mean stresses seems harsh at first, using the estimated cyclic material parameters from Vickers hardness and omitting the mean stress (full triangles), the LSA gives a result very close to the experimentally obtained number of cycles for the clinched joint with bottom thickness of $1.0 \mathrm{~mm}$ (circles).

\section{Conclusions}

In the present study, a fatigue life estimation with the Local Strain Approach is performed for a clinched joint manufactured from the aluminium alloy EN AW-6060 T66 incorporating the impact of cold forming on the cyclic material properties. Experimentally obtained fatigue life for failure criteria fracture and crack initiation are presented and compared to the fatigue life estimation based on numerical simulation with elastic-plastic material behaviour. Following conclusions were reached:

a. With respect to the failure criterion fracture, clinched joint variants with bottom thickness $1.0 \mathrm{~mm}$ and $1.4 \mathrm{~mm}$, respectively, show similar fatigue lives. This can be attributed to comparable joint properties, such as neck thickness and undercut.

b. Using cyclic material properties of sheet material in as received state results in a very conservative fatigue life estimation. Therefore, change in cyclic material properties due to cold forming need to be considered in fatigue life estimation.

\section{Acknowledgements}

The research project was carried out in the framework of the industrial collective research programme (AiF-Nr. 20300BR). It was supported by the Federal Ministry for Economic Affairs and Energy (BMWi) through the AiF (German Federation of Industrial Research Associations eV) based on a decision taken by the German Bundestag.

\section{References}

1. X. He, Sci Technol Adv Mater 17, 1 (2017)

2. J. Mucha, Mater. Des. 32, 4943-4954 (2011)

3. S. Coppieters, Phd. thesis (2012)

4. F. Lambiase, A. Di Ilio, THIN WALL STRUCT 85, 71-80 (2014)

5. F. Lambiase, A. Di Ilio, A. Paoletti, Int J Adv Manuf Technol 77, 1295-1304 (2015)

6. C.J. Lee, J.Y. Kim, S.K. Lee, D.C. Ko, B.M. Kim, J. Mech. Sci. Technol. 24, 123-126 (2010)

7. Ch.R. Bielak, M. Böhnke, R. Beck, M. Bobbert, G. Meschut, J Adv Join Process 3 (2021)

8. L. Ewenz, J. Kalich, M. Zimmermann, U. Füssel, K. Eng. Mater. 883, 65-72 (2021) 
9. J.B. Kim, H.K. Kim, FFEMS 38, 661-672 (2015)

10. B. Spak, M. Schlicht, K. Nowak, M. Kästner, P. Froitzheim, W. Flügge, M. Fiedler, International Conference on Fatigue Design, 9th Edition (2021, in review)

11. H.H. Crews, H.F. Hardrath, Exp Mech 6, 313-320 (1966)

12. H. Neuber, J Appl Mech 28, 4 (1961)

13. W. Ramberg, W.R. Osgood, Technical Note No. 902 (1943)

14. G. Masing, Proceedings of the 2nd International Congress for Applied Mechanics, Zürich, pp. 332-335 (1926)

15. K.N. Smith, P. Watson, T.H. Topper, J Mater 5, 767-778 (1970)

16. M. Wächter, A. Esderts, LCF8. Eighth International Conference on Low Cycle Fatigue (2017)

17. E. Voce, Journal of the Institute of Metals 74, 537-562 (1948)

18. D. Kühne, B. Spak, M. Kästner, A. Brosius, M. Fiedler, Arch Appl Mech 91, 36933707 (2021)

19. P. Sjöström, S.A.H. Johansson, Mater. Sci. Forum 490-491, 404-408 (2005)

20. Society of Materials Science in Japan, Data Book on Fatigue Strength of Metallic Materials (1996)

21. M. Wächter, Phd. thesis (2016)

22. L. Winter, K. Hockauf, T. Lampke, IOP Conf. Series: Mater. Sci. Eng. A 480 (2019) 